\title{
A produção científica sobre moradia estudantil: um estudo dos artigos publicados no Portal de Periódicos da CAPES
}

\author{
Scientific production on student housing: a study of the articles published \\ in the CAPES Portal of Periodicals
}

\section{La producción científica sobre vivienda estudiantil: un estudio de los artículos publicados en el Portal de Periódicos de la CAPES}

\author{
Joice Rejane Pardo Maurell ${ }^{1}$ \\ Celiane Costa Machado ${ }^{2}$
}

\begin{abstract}
Resumo
Este estudo se insere em uma pesquisa, que culminará em uma tese de doutorado, pelo Programa de PósGraduação em Educação em Ciências, da Universidade Federal do Rio Grande - FURG. Buscou identificar e analisar os artigos científicos, que tiveram como tema a Moradia Estudantil, publicadas nos últimos cinco anos. Para tanto, metodologicamente, optou-se por fazer um mapa teórico (BIEMBENGUT, 2008) a partir de uma busca, por assunto, no Portal de Periódicos da CAPES, com as expressões "Moradia Estudantil", "Casa do Estudante". e "Moradia Universitária". Inicialmente, foram identificados 50 publicações, entre os artigos revisados por pares, que após inserido o filtro "data de publicação 2014-2018" totalizaram 27. Na sequência, foi realizada a leitura desses resumos, considerando na produção do mapa teórico, as temáticas relacionadas a moradia estudantil, com foco na educação. Com esse recorte foram identificados e analisados sete artigos, que discorreram sobre as memórias, história/trajetórias dos estudantes, a assistência estudantil como campo político e os processos de aprendizagem dos moradores. O estudo mostrou que não existem muitas publicações que abordam a temática Moradia Estudantil na área da educação, pois grande parte da pesquisas têm contemplado ações e investigações sobre saúde e nutrição. Evidenciou, também, que as publicações na área da educação são temporais, no período compreendido entre 2016 e 2018 e localizadas, pois cinco pesquisas foram realizadas nas e/ou sobre as Casas de Universidades do Rio Grande do Sul. No que tange as revistas, nenhum dos sete artigos foi publicado no mesmo periódico, sendo cinco deles de âmbito internacional.
\end{abstract}

Palavras-Chave: CAPES; Mapeamento; Moradia Estudantil; Portal de Periódicos; Produção Científica

\section{Summary}

This study is part of a research, culminating in a PhD thesis, by the Graduate Program in Science Education, Federal University of Rio Grande - FURG. It sought to identify and analyze the scientific articles, which had the theme of Student Housing, published in the last five years. For that, methodologically, it was decided to make a theoretical map (BIEMBENGUT, 2008) from a search, by subject, in the Portal of Periodicals of CAPES, with the expressions "Student Housing", "Student House". and "University Housing". Initially, 50 publications were identified among the peer-reviewed articles, which, after insertion of the "publication date 2014-2018" filter, totaled 27. Following this, the abstracts were read, considering the production of the theoretical map, related topics the student residence, with a focus on education. With this cut, seven articles were identified and analyzed, which discussed the memories, the history / trajectories of the students, the student assistance as a political field and the learning processes of the residents. The study showed that there are not many publications that address the issue of Student Housing in the area of education, since much of the research has contemplated

\footnotetext{
${ }^{1}$ Mestre em Educação Ambiental; Universidade Federal do Rio Grande - FURG; Rio Grande, Rio Grande do S e Brasil; joicerejane@furg.br.

${ }^{2}$ Doutora em Matemática Aplicada; Universidade Federal do Rio Grande do Sul - UFRGS; Porto Alegre, Rio Grande do Sul e Brasil; celianemachado@furg.br
} 
actions and investigations on health and nutrition. It was also evidenced that the publications in the area of education are temporary in the period between 2016 and 2018 and located, since five surveys were conducted in and / or on the Houses of Universities of Rio Grande do Sul. Regarding the journals, none of the seven articles was published in the same periodical, five of them of international scope.

Keywords: CAPES; Mapping; Student house; Portal of Journals; Scientific production

\section{Resumen}

Este estudio se inserta en una investigación, que culminará en una tesis de doctorado, por el Programa de Postgrado en Educación en Ciencias, de la Universidad Federal del Río Grande - FURG. Buscó identificar y analizar los artículos científicos, que tuvieron como tema la Vivienda Estudiantil, publicados en los últimos cinco años. Para ello, metodológicamente, se optó por hacer un mapa teórico (BIEMBENGUT, 2008) a partir de una búsqueda, por tema, en el Portal de Periódicos de la CAPES, con las expresiones "Vivienda Estudiantil", "Casa del Estudiante". y "Vivienda Universitaria". En primer lugar, se identificaron 50 publicaciones, entre los artículos revisados por pares, que tras insertar el filtro "fecha de publicación 2014-2018" totalizaron 27. En consecuencia, se realizó la lectura de estos resúmenes, considerando en la producción del mapa teórico, las temáticas relacionadas la vivienda estudiantil, con foco en la educación. Con este recorte se identificaron y analizaron siete artículos, que discurrieron sobre las memorias, historia / trayectorias de los estudiantes, la asistencia estudiantil como campo político y los procesos de aprendizaje de los habitantes. El estudio mostró que no existen muchas publicaciones que abordan la temática Vivienda Estudiantil en el área de la educación, pues gran parte de las investigaciones han contemplado acciones e investigaciones sobre salud y nutrición. En el período comprendido entre 2016 y 2018 y localizadas, ya que se realizaron cinco investigaciones en las y / o sobre las Casas de Universidades de Rio Grande do Sul. En lo que se refiere a las revistas, ninguno de los siete artículos fue publicado en el mismo periódico, siendo cinco de ellos de ámbito internacional.

Palabras clave: CAPES; mapeo; Vivienda Estudiantil; Portal de Periódicos; Producción Científica

\section{Introdução}

O Programa do Governo Federal de Apoio a Planos de Reestruturação e Expansão das Universidades Federais Brasileiras - REUNI, criado em 2007, promoveu as condições para expandir o acesso ao ensino superior, principalmente pelas camadas mais populares. Diante de tais transformações, ocorreram grandes avanços em torno de políticas de assistência estudantil, para que pudessem garantir, também, a permanência dos estudantes durante seu período de formação, reduzindo a evasão acadêmica.

Dentre as inúmeras pautas, a moradia estudantil destacou-se enquanto política de assistência estudantil, prevista nas áreas do Programa Nacional de Assistência Estudantil (PNAES), publicado em 2010, como estratégia que viabilizaria a migração estudantil, dos estudantes de baixa renda, que passaram a ingressar em universidades federais públicas, em diferentes regiões do país.

Assim, no atual contexto das universidades públicas brasileiras, a moradia estudantil se coloca como um tema de pesquisa com fundamental importância, pois o seu crescimento no número de vagas a partir do REUNI é expressivo, além de ser um espaço de protagonismo estudantil, vivência na coletividade e de mobilização da juventude. 
Dito isso, o presente estudo buscou identificar e analisar os artigos científicos revisados por pares, que tiveram como tema a Moradia Estudantil, publicadas nos últimos cinco anos e disponíveis no Portal de Periódicos da Coordenação de Aperfeiçoamento de Pessoal de Nível Superior (CAPES). Metodologicamente, optou-se pela produção de um mapa teórico (BIEMBENGUT, 2008), colocando no buscador assunto as expressões "Moradia Estudantill", "Casa do Estudante" e "Moradia Universitária".

Na primeira busca foram identificadas 50 publicações, entre os artigos revisados por pares, que após inseridos o filtro "data de publicação 2014-2018" totalizaram 27. Depois da leitura dos resumos foram selecionados os artigos relacionados à área da educação, totalizando sete publicações.

A organização do texto prevê, além da introdução e das considerações finais, um breve contexto histórico da assistência e da moradia estudantil no Brasil, os procedimentos metodológicos do mapa teórico - identificação, classificação/organização e reconhecimento/análise (BIEMBENGUT, 2008) e, na sequência, a descrição e análise dos artigos, organizados em três quadros, um para cada expressão de busca.

\section{Conceito e contexto da assistência e das moradias estudantis no Brasil}

A Reforma Francisco Campos, de 1931, representa a primeira iniciativa de regulamentação da política de assistência estudantil no Brasil. Depois disso, na Constituição de 1946, a assistência estudantil tornou-se obrigatória para todos os sistemas de ensino, garantido pelo art. $\mathrm{n}^{\mathrm{o}}$ 172, afirmando que cada Sistema de Ensino teria, obrigatoriamente, serviços de assistência educacional que assegurassem aos estudantes necessitados, condições de eficiência escolar (BRASIL, 1946). A referida constituição, também, deixava evidente o conceito que o Estado defendia como Política de Assistência Estudantil, uma medida de ajuda aos estudantes necessitados, considerando a situação econômica de suas famílias.

Entretanto, a Lei de Diretrizes e Bases (LDB) 4.024, de 1961, passou a considerar a assistência estudantil como algo que está implícito ao direito à educação (BRASIL, 1961), fazendo com que o Governo Federal criasse, em 1970, o Departamento de Assistência ao Estudante (DAE), que consistia no setor de âmbito ministerial, com o objetivo de manter uma política de assistência ao estudante universitário em nível nacional, priorizando os programas de alimentação, moradia, assistência médica e odontológica (BARRETO, 2014).

O movimento estudantil, de forma geral, sempre teve uma ligação muito forte com as moradias estudantis e, nesse sentido, faz-se um recorte em relação ao objeto desse movimento 
investigativo, assumindo o conceito de 'Casa do Estudante' a partir das orientações disponíveis na página da Secretaria Nacional de Casas de Estudante (SENCE, 2011).

\begin{abstract}
Casa de Estudante é todo o espaço destinado à moradia de estudantes, podendo receber as seguintes denominações: alojamento estudantil, residência estudantil, casa de estudante (universitária, secundária, pós-graduação, autônoma, estadual, municipal), repúblicas e outras, independente da renda dos(as) moradores(as). [...] Existem três tipos básicos de Moradia Estudantil: Residência Estudantil, Casa Autônoma de Estudantes e República Estudantil (SENCE, 2011).
\end{abstract}

No que tange a análise proposta, assume-se com corpus dessa investigação as publicações disponíveis no Portal de Periódicos da CAPES dos últimos cinco anos, que tiveram como tema a Moradia Estudantil do tipo Residência Estudantil, ou seja, "[...] a moradia de propriedade das Instituições de Ensino Superior e/ou das Instituições de Ensino Secundaristas Públicas." (SENCE, 2011).

Contudo, cabe salientar que a Residência Estudantil não foi o primeiro tipo de Moradia Estudantil do Brasil, pois as primeiras que se tem notícia foram as "Repúblicas" de Ouro Preto/MG, no período imperial (XIX), quando grupos de estudantes com ideais republicanos se juntaram e foram morar em casarões e sobrados. Nesse momento, o surgimento dessas repúblicas foi uma ação política, sendo que no período da Ditadura CivilMilitar (1964-1985), as casas de estudantes também serviram como locais estratégicos de refúgio e resistência ao regime. Em 1987, o movimento melhor se articulou nacionalmente com a criação da SENCE - Secretaria Nacional de Casas de Estudantes (SENCE, 2011).

Na década de 90, com o avanço do neoliberalismo, a Assistência Estudantil foi considerada 'gasto desnecessário' e nessa ótica foi extinta a rubrica específica que garantia o repasse financeiro para esse fim, às universidades públicas. Nos anos 2000, a luta pela rubrica específica da assistência estudantil cresce com a criação PNAES, que garantiu, inicialmente, três anos (2008-2010) de verbas para as Instituições de Ensino Superior (SENCE, 2011).

Contudo, a Constituição de 1988 e a LDB 9394, de 1996, já apontavam para novas garantias de direito à educação pública de nível superior (BRASIL, 1996). Nessa vertente o conceito de “Ações Afirmativas" passou a ser discutido. De acordo com Gomes (2002, p. 132) as ações afirmativas são

políticas públicas (e também privadas) voltadas à concretização do princípio constitucional da igualdade material e a neutralização dos efeitos da discriminação racial, de gênero, de idade, de origem, nacional e de compleição física. Impostas ou sugeridas pelo estado, por seus entes vinculados e até mesmo por entidades puramente privadas, elas visam a combater não somente as manifestações flagrantes de discriminação de fundo cultural, estrutural, enraizada na sociedade (GOMES, 2002, p. 132). 
Assim, para promover e/ou ampliar as condições de permanência à Educação Superior pública federal, dos estudantes que ingressaram por ações afirmativas foi publicado o decreto n 7.234 , de 19 de julho de 2010, que dispunha sobre o PNAES. Segundo o Programa,

as ações de assistência estudantil deverão ser desenvolvidas nas seguintes áreas: moradia estudantil; alimentação; transporte; atenção à saúde; inclusão digital; cultura; esporte; creche; apoio pedagógico e acesso, participação e aprendizagem de estudantes com deficiência, transtornos globais do desenvolvimento e altas habilidades e superdotação (BRASIL, 2010).

Fez-se necessário promover essa discussão porque todas as publicações analisadas neste artigo versam sobre uma das áreas garantidas pelo PNAES - a moradia estudantil - e, foram produzidos no período posterior a publicação desse decreto, sendo duas de 2018; quatro de 2017 e uma de 2016, ou seja, evidenciam o modelo de assistência e de moradia estudantil a partir dessas orientações. Concluído o histórico dessas políticas no Brasil, o próximo tópico propõe-se a traçar um mapa teórico (BIEMBENGUT, 2008) das publicações destacadas no portal de periódicos da CAPES.

\section{Metodologia: a construção do mapa teórico}

O mapa teórico é uma metodologia que tem seus procedimentos organizados em três etapas: identificação, classificação/organização e reconhecimento/análise (BIEMBENGUT, 2008). Segundo a referida autora o mapa teórico

não se restringe a um mero levantamento e organização de dados, e tampouco ao traçado de um mapa. É um forte constituinte não somente para reconhecimento ou análise dos dados, mas, especialmente, por proporcionar um vasto domínio sobre o conhecimento existente da área investigada. Suscita-nos desenvolver fórmulas ou meios adequados para compreensão, análise e representação dos dados ou das informações investigadas e conhecer as questões que envolvem as ações educacionais ou pedagógicas à medida que essas questões se revelem ou revelem movimentos resultantes das circunstâncias. (BIEMBENGUT, 2008, p. 90)

Dentro da proposta de organização de um mapa teórico das publicações, na etapa de identificação dos trabalhos, realizou-se uma busca por assunto no Portal de Periódicos da CAPES, com as expressões "Moradia Estudantil", "Casa do Estudante" e "Moradia Universitária". Inicialmente, foram identificados 50 artigos revisados por pares, que inserido o filtro “data de publicação 2014-2018” totalizaram 27, como mostra o Quadro 1.

Quadro 1: Número de publicações relacionadas à Moradia Estudantil, Casa do Estudante e Moradia Universitária, nos periódicos da CAPES

\begin{tabular}{|l|l|r|}
\hline Expressão pesquisada & Filtro & Publicações \\
\hline \multirow{2}{*}{ Moradia Estudantil } & Artigos revisados por pares & 24 \\
\cline { 2 - 3 } & Data de Publicação 2014-2018 & 14 \\
\hline \multirow{2}{*}{ Casa do Estudante } & Artigos revisados por pares & 22 \\
\cline { 2 - 3 } & Data de Publicação 2014-2018 & 12 \\
\hline Moradia Universitária & Artigos revisados por pares & 04 \\
\hline
\end{tabular}


RELACult - Revista Latino-Americana de Estudos em Cultura e Sociedade

\begin{tabular}{|c|c|c|}
\hline & Data de Publicação 2014-2018 & 01 \\
\hline \multicolumn{3}{|c|}{ Total } \\
\hline Artigos revisados por pares & & 50 \\
\hline Artigos revisados por pares & $2014-2018$ & 27 \\
\hline
\end{tabular}

Depois de selecionados os 27 artigos dos últimos cinco anos, os resumos foram organizados em um documento único, para a identificação daqueles que tinham relação com a área da educação. Para Biembengut (2008, p. 91)

feita esta primeira identificação, lemos os resumos das produções e, então, efetuamos seleção e classificação, organizando-os na forma de catálogo, rol ou descrição pormenorizada. Se o número de pesquisas levantado for muito grande, faremos uma primeira seleção segundo pressupostos que indiquem os relevantes para apoiar ou fundar o problema da pesquisa. Quanto mais resumos tomarmos para uma primeira inteiração com o tema, melhores condições reuniremos para escolher os que sustentarão nossa pesquisa e comporão nosso mapa.

Assim, feita a leitura dos resumos, a etapa de classificação/organização do mapa teórico evidenciou sete pesquisas na área da educação, pois a grande maioria dos trabalhos foram escritos por pesquisadores da saúde, abordando questões como prevenção de doenças e nutrição. Atinente, as sete produções selecionadas, consideradas na leitura dos resumos como relacionadas a área da educação, apresentaram como temáticas subjacentes as memórias, histórias/trajetórias dos estudantes na Casa, assistência estudantil como campo político e os processos de aprendizagem dos estudantes moradores.

Nesse sentido, com o objetivo de identificar e analisar as produções científicas que tiveram como tema a Moradia Estudantil, publicadas nos últimos cinco anos e disponíveis no Portal de Periódicos da CAPES, a terceira etapa, de reconhecimento/análise, faz uma escrita descritiva dos sete artigos evidenciados, destacando a temática subjacente, o contexto, objetivos, metodologias e resultados. Para Biembengut (2008, p. 93)

a partir dessa seleção, passamos a tomar ciência desses trabalhos e a situar conhecimentos relevantes para a elucidação do problema que pretendemos investigar. Não se trata apenas de levantar as pesquisas existentes e relatá-las como parte de sequência histórica linearmente trabalhada, mas, sim, identificar os pontos relevantes ou significativos que nos valham como guia para compreender os segmentos já pesquisados e expressos de forma a nos permitir elaborar um sistema de explicação ou de interpretação.

Na sequência, organizou-se um quadro para cada expressão de busca, identificando o título do trabalho, ano de publicação, autores e o periódico. Biembengut (2008, p. 95) fala do processo de reconhecimento e categorização como a etapa necessária para "compreender os fatos, ponderá-los, compará-los, rejeitar alguns, conservar outros, reunir elementos que possam vir a se constituir em excepcional embasamento ao pesquisador". Ademais, segundo a referida autora 
para reconhecer e/ou analisar os trabalhos acadêmicos tomamos as sínteses por nós elaboradas e procuramos classificá-los de acordo com algum critério, agrupando-os. É essencial termos claros os conceitos e as definições relativos ao tema de pesquisa que pretendemos efetuar como parâmetro ou referência. Reconhecer significa identificar e assinalar concepções teóricas e principais resultados. Analisar implica combinar vários dados ou resultados específicos em um mais geral, realizando combinações por meio de associações em função de similaridades, contraste ou proximidade, vizinhança (BIEMBENGUT, 2008, p. 95).

Seguindo esses procedimentos metodológicos, o tópico a seguir apresentará a análise a partir de três quadros, com o processo de reconhecimento/análise dos artigos, organizados a partir das expressões de busca, utilizadas no Portal de Periódico da CAPES.

\section{Descrição e análise das publicações}

Apesar da pesquisa com os termos "Moradia Estudantil", Casa do Estudante" e "Moradia Universitária" terem mostrado 27 publicações, ou seja, um número razoável de artigos no período 2014-2018, a leitura dos resumos evidenciou uma produção discreta na área da educação e, ainda, temporal e localizada. Isso porque todos os sete artigos foram publicados entre os anos de 2016 e 2018, sendo que cinco relataram pesquisas realizadas em universidades do Rio Grande do Sul e a maioria das publicações, quatro, estão relacionadas a expressão de busca "Moradia Estudantil".

No Quadro 2 foram destacados quatro artigos, cujo a expressão de busca foi "Moradia Estudantil'. Embora o recorte temporal tenha sido definido a partir de 2014, só foram encontrados artigos na área da educação com a referida expressão a partir de 2016, sendo dois em 2017, todos em periódicos diferentes e três de âmbito internacional.

Quadro 2: Publicações relacionadas à Moradia Estudantil, nos periódicos da CAPES

\begin{tabular}{|c|c|c|c|}
\hline Título & Ano & Autor & Periódico \\
\hline $\begin{array}{l}\text { Programa Nacional de assistência } \\
\text { estudantil: do protagonismo da une } \\
\text { aos avanços da luta por direitos, } \\
\text { promovidos pelo FONAPRACE } \\
\text { (PNAES: da UNE } \\
\text { FONAPRACE) }\end{array}$ & 2016 & $\begin{array}{l}\text { JESUS, Luciano Nascimento de } \\
\text { MAYER, Andre Luiz Monteiro } \\
\text { CAMARGO, Pedro Luiz Teixeira } \\
\text { de }\end{array}$ & $\begin{array}{l}\text { Acta } \quad \text { Scientiarum } \\
\text { Education (UEM) }\end{array}$ \\
\hline $\begin{array}{l}\text { Tácitas e marginais: memórias das } \\
\text { casas de estudante autônomas de } \\
\text { Porto Alegre e as possibilidades } \\
\text { para a história da educação }\end{array}$ & 2017 & HINTERHOLZ, Marcos Luiz & História da Educação \\
\hline 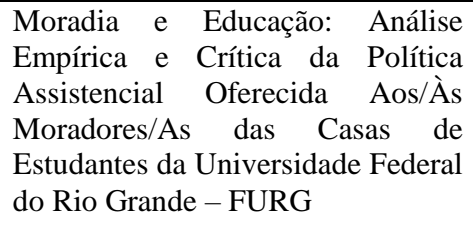 & 2017 & $\begin{array}{l}\text { CABRAL JUNIOR, Luciano } \\
\text { Roberto Gulart } \\
\text { GONÇALVES, Jean Carlo Flores } \\
\text { COSTA, José Ricardo Caetano }\end{array}$ & $\begin{array}{l}\text { Brazilian Journal of } \\
\text { Empirical Legal Studies }\end{array}$ \\
\hline $\begin{array}{l}\text { Concepções de ingressantes } \\
\text { Moradia Estudantil sobre } \\
\text { as }\end{array}$ & 2018 & MAURELL, Joice Rejane Pardo & $\begin{array}{l}\text { Revista Latino Americana } \\
\text { de Estudos em Cultura e }\end{array}$ \\
\hline
\end{tabular}


RELACult - Revista Latino-Americana de Estudos em Cultura e Sociedade

\begin{tabular}{|l|l|l|l|}
\hline disciplinas Cálculo & & MACHADO, Celiane Costa & Sociedade \\
\hline
\end{tabular}

Fonte: elaborado pelas autoras

Jesus, Mayer e Camargo (2016) no artigo intitulado "Programa Nacional de assistência estudantil: do protagonismo da une aos avanços da luta por direitos, promovidos pelo FONAPRACE (PNAES: da UNE a FONAPRACE)" buscou demonstrar que a construção de uma Política Nacional de Assistência Estudantil, em nível de política de Estado, é uma ‘construção histórica de várias mãos'. O texto destaca as contribuições do Fórum Nacional de Pró-Reitores de Assuntos Comunitários e Estudantis (FONAPRACE) e da União Nacional dos Estudantes (UNE) na constituição do PNAES.

A referida pesquisa, de cunho bibliográfico e documental, deteve-se a evidenciar parte da história descontínua da Educação Brasileira, demonstrando algumas implicações que colaboraram para a não garantia de acesso, permanência e conclusão da graduação no Ensino Superior para a maioria da população brasileira. Os autores concluíram o estudo defendendo que, apesar dos avanços conseguidos na última década, por meio da pressão dos movimentos sociais de educação, tais avanços ainda não foram suficientes.

No artigo "Tácitas e marginais: memórias das casas de estudante autônomas de Porto Alegre e as possibilidades para a história da educação" Hinterholz (2017) defende que a temática Moradia Estudantil Universitária ainda é pouco abordada pela historiografia, refletindo que a redução destes espaços decorrem do seu caráter assistencial e das abordagens que não as contemplam enquanto lugar de formação e de troca de saberes.

A partir de perspectivas abertas pela vertente da História Cultural, o autor apresentou o surgimento e a organização de três casas de estudantes autônomas de Porto Alegre - Aparício Cora de Almeida (Ceuaca); Associação Casa de Estudantes Juventude Universitária Católica Casa 7 ( JUC-7) e Casa Estudantil Universitária de Porto Alegre (Ceupa). Na conclusão do texto o autor detém-se a defender a relevância da inscrição da referida temática no campo da História da Educação, buscando ainda repensar as fontes e algumas questões importantes para pesquisas relacionadas ao tema (HINTERHOLZ, 2017).

Cabral Junior, Gonçalves e Costa (2017), iniciam a escrita do artigo "Moradia e Educação: análise empírica e crítica da política assistencial oferecida aos/às moradores/as das Casas de Estudantes da Universidade Federal do Rio Grande - FURG” mostrando que para facilitar o acesso e permanência de estudantes no ensino superior foi criado o Programa PNAES. Segundo os autores, esse programa tem como um de seus objetivos propiciar moradia estudantil para aqueles que desse benefício necessitar. 
O estudo teve como corpus investigativo a Universidade Federal do Rio Grande FURG, que disponibiliza assistência estudantil aos estudantes, incluindo a moradia. A pesquisa de cunho qualitativo e quantitativo, que teve como método a abordagem dedutiva e de procedimento monográfico, objetivou analisar empírica e criticamente a política assistencial oferecida aos/às moradores/as das Casas de Estudantes da FURG. Para tanto, disponibilizou-se um questionário para os/as estudantes moradores dessas Casas de Estudantes e as respostas foram analisadas a partir da bibliografia e da legislação correlatas (CABRAL JUNIOR; GONÇALVES e COSTA, 2017).

Os autores defenderam a relevância da assistência estudantil para a redução das desigualdades socioeconômicas e para a qualidade da formação dos/as estudantes, como forma de promover a justiça social e a dignidade da pessoa humana. Na conclusão do estudo, os autores defenderam que movimentos estudantis possuem papel crucial na construção e na reivindicação de direitos em tal âmbito e apontaram algumas medidas, que emergiram nos questionários, a serem tomadas para a melhoria da assistência estudantil da FURG (CABRAL JUNIOR; GONÇALVES e COSTA, 2017).

No artigo "Concepções de ingressantes da Moradia Estudantil sobre as disciplinas Cálculo", Maurell e Machado (2018) localizaram o estudo como a etapa inicial de uma pesquisa, que culminará em uma tese de doutorado. Metodologicamente, as autoras produziram um mapa do campo (BIEMBENGUT, 2008) dividido em dois movimentos. No primeiro movimento foram levantados dados que antecedem o ingresso na Universidade, como: proveniência regional, gênero, idade e rede de Educação Básica e, posteriormente, dados acadêmicos, como: modalidade de ingresso pelo Sistema de Seleção Unificada - SISU, curso, a disciplina Cálculo em que estavam matriculados e suas respectivas ementas. Traçado o perfil dos sujeitos, foi realizado um segundo movimento, no qual foram entrevistados os sujeitos da pesquisa.

Nas entrevistas os estudantes definiram a disciplina Cálculo em uma palavra e relataram as suas estratégias de estudos, avaliando-as. O estudo deteve-se a analisar as respostas à provocação "Defina a disciplina cálculo em uma palavra.”, a partir da qual emergiram expressões como: divisor de águas, paixão, medo, difícil, possibilidades, empecilho e necessário.

Com a expressão de busca "Casa do Estudante" foram selecionados dois artigos, expressos no Quadro 3, para o processo de reconhecimento/análise. Destaca-se nesse quadro que o pesquisador Marcos Luiz Hinterholz, que publicou um texto sobre Moradia Estudantil no periódico 'História da Educação' em 2017, teve uma outra publicação sobre a temática em 
2018, na revista 'Espacio, Tiempo y Education', evidenciando o envolvimento do pesquisador com a temática discutida neste artigo.

Quadro 3: Publicações relacionadas à Casa do Estudante, nos periódicos da CAPES

\begin{tabular}{|l|l|l|l|}
\hline Título & Ano & Autor & Periódico \\
\hline $\begin{array}{l}\text { Geografia e Estudo do Lugar: } \\
\text { a Casa do Estudante Universitário } \\
\text { II - UFSM/Santa Maria/RS }\end{array}$ & 2017 & HERRMANN, Gustavo & $\begin{array}{l}\text { Boletim } \\
\text { Geográfico do Rio } \\
\text { Grande do Sul }\end{array}$ \\
\hline $\begin{array}{l}\text { Casa do Estudante Universitário } \\
\text { Aparício Cora de Almeida (1963- } \\
\text { 1981) }\end{array}$ & 2018 & HINTERHOLZ, Marcos Luiz & $\begin{array}{l}\text { Espacio, Tiempo y } \\
\text { Educación }\end{array}$ \\
\hline
\end{tabular}

Fonte: elaborado pelas autoras

Herrmann e Costa (2017) no artigo "Geografia e estudo do lugar: a Casa do Estudante Universitário II - UFSM/Santa Maria/RS" promove uma discussão sobre a Geografia Cultural, apresentando um estudo sobre o conceito de Lugar proposto por Yi-Fu Tuan. O estudo evidenciou a Casa do Estudante Dois (CEUII) da Universidade Federal de Santa Maria como um espaço emotivo e relacional, depósito de intenções e afetividades de seus moradores. Metodologicamente, os autores utilizaram mapas mentais como instrumento de análise, nos quais buscaram experiências vivenciadas pelos estudantes na CEUII, para entender suas relações objetivas e subjetivas com o lugar onde vivem, entendendo que as mesmas, também, estão inseridas em um período de suas vidas.

$\mathrm{Na}$ conclusão do artigo, os autores destacam que os mapas mentais demonstraram as diversas maneiras possíveis de representar o lugar, tanto na sua forma física material, com objetos que estão visíveis ao olhar e presente no espaço; como na forma imaterial possibilitando evocar elementos afetivos que estão ligados a psique humana. Ainda, segundo os autores, com os mapas mentais foi possível notar algumas problemáticas relacionadas à Casa do Estudante, como o barulho de vizinhos, incompatibilidade de relacionamento e as poucas áreas de lazer. Contudo, concluem que no período de residência os estudantes moradores desenvolvem formas diferentes de sentimentos pelo lugar, com experiências tecidas positivamente, que contribuem para o desenvolvimento social, de interação com a diversidade e construção de diferentes sociabilidades (HERRMANN e COSTA, 2017).

Hinterholz (2018) no artigo "Casa do Estudante Universitário Aparício Cora de Almeida (1963-1981)" faz um recorte da sua dissertação de mestrado, no qual fez um estudo historiográfico sobre a Casa do Estudante Universitário Aparício Cora de Almeida (CEAUCA), fundada no ano de 1934 em Porto Alegre - RS. No artigo, o autor define a Casa como uma instituição educativa, fazendo a análise de documentos e narrativas de memória dos moradores egressos. 
Segundo o autor, o objetivo do estudo foi promover uma noção ampliada do processo educativo presente nas moradias estudantis, para além da escolarização e buscar na construção da história da instituição, práticas e experiências dos sujeitos habitantes e analisar os modos como a Casa foi significada por cada um dos entrevistados. No referencial, a pesquisa posicionou-se no campo da História da Educação, utilizando os postulados da História Cultural. Metodologicamente, a pesquisa assumiu elementos da História Oral e da análise documental histórica, respectivamente (HINTERHOLZ, 2018).

Na conclusão do estudo, o autor evidenciou que foram recorrentes tanto nas narrativas quanto no discurso dos periódicos analisados, a atribuição de um sentido formativo à experiência de moradia estudantil. As narrativas contemplaram, ainda, o contexto político da época e suas implicações nas cisões ideológicas constituídas no interior da Casa, que apareceram fortemente na maneira como os sujeitos contam suas memórias sobre as vivências na instituição, sendo as mesmas inscritas e elaboradas de diferentes formas nas narrativas pessoais dos sujeitos entrevistados (HINTERHOLZ, 2018).

A expressão de busca "Moradia Universitária", evidenciou um artigo, apresentado no Quadro 4.

\begin{tabular}{|l|c|l|l|}
\hline \multicolumn{2}{|c|}{ Quadro 4: Publicações relacionadas à Moradia Universitária, nos periódicos da CAPES } \\
\hline Título & Ano & Autor & Periódico \\
\hline $\begin{array}{l}\text { Microagressões no ensino superior } \\
\text { nas vias da Educação Matemática }\end{array}$ & 2017 & $\begin{array}{l}\text { SILVA, Guilherme da } \\
\text { POWELL, Arthur }\end{array}$ & $\begin{array}{l}\text { Revista } \\
\text { Latinoamericana de } \\
\text { Etnomatemática }\end{array}$ \\
\hline
\end{tabular}

Fonte: elaborado pelas autoras

No artigo intitulado "Microagressões no ensino superior nas vias da Educação Matemática", Silva e Powell (2017) não discorrem especificamente sobre o tema Moradia, embora o mesmo apareça muitas vezes no texto, mas refletem sobre a Assistência Estudantil e a Educação Matemática, a partir do conceito de Microagressões, que os autores definem como formas sutis de insultos verbais, não verbais e visuais, direcionadas a indivíduos com base em raça, gênero, etnia, classe social, dialeto ou religião. Essa definição é utilizada no artigo para refletir sobre a relação professor-aluno no Ensino Superior, especialmente nas disciplinas da área das exatas, as quais os estudantes que ingressam por baixa renda e/ou são assistidos por benefícios da Assistência Estudantil, frequentemente apresentam dificuldades de aprendizagem.

Segundo os autores, as microagressões também expressam uma forma de racismo e no contexto da educação em nível superior pode provocar dificuldades acadêmicas e de adaptação ao ambiente universitário. Além disso, buscaram refletir sobre o conceito de 
microagressões e suas possíveis implicações para a permanência e progresso de estudantes pertencentes a grupos sub-representados no ensino superior, as quais geralmente estão relacionadas com questões de gênero, raça, etnia, classe social, orientação sexual, entre outros (SILVA e POWELL, 2017).

Para atender ao referido objetivo os autores optaram pela revisão de estudos e pesquisas, bem como por reflexões baseadas em dados de experiências com microagressões relatadas por estudantes de cursos superiores da área das Ciências Exatas, beneficiados por ações afirmativas. Na conclusão do trabalho foi destacado que a principal característica das microagressões sofridas no meio acadêmico repousam na natureza sutil e nebulosa das ofensas (SILVA e POWELL, 2017).

\section{Considerações Finais}

A produção do mapa teórico sobre o tema "Moradia Estudantil", representada também pelas expressões de busca "Casa do Estudante" e "Moradia Universitária", disponíveis no portal de periódicos da CAPES, mostrou-se significativa nos últimos cinco anos, totalizando 27 artigos. Contudo, como as publicações sobre Moradia Estudantil tem, frequentemente, como área subjacente a saúde e a nutrição, a leitura dos resumos colocou em evidência sete publicações na área da educação. Os referidos artigos versam basicamente sobre memórias, histórias/trajetórias dos estudantes na Casa, assistência estudantil como campo político e os processos de aprendizagem dos estudantes moradores.

Em relação ao período, todos os artigos foram publicados entre 2016 e 2018. Sobre os periódicos de submissão, nenhum dos sete artigos foi publicado no mesmo e cinco deles são de âmbito internacional. No que tange ao envolvimento dos pesquisadores com a temática "Moradia Estudantil", identificou-se um autor com dois artigos diferentes, publicados um em 2017 e outro em 2018, em revistas distintas. Entretanto, ambos artigos descrevem pesquisas sobre moradias estudantis de Porto Alegre, especificamente a Ceuaca, a JUC-7 e a Ceupa, sendo o segundo artigo uma pesquisa mais aprofundada sobre o Ceuaca.

O mapa ainda evidenciou dois trabalhos sobre a Moradia Estudantil da FURG, com temas relacionados aos auxílios/benefícios dos estudantes moradores e os processos de aprendizagem e, outro realizado na Casa do Estudante Universitário (CEU II) da UFSM, abordando a temática "Geografia do Lugar".

Concluindo, o estudo teórico evidenciou que as publicações sobre "Moradia Estudantil", disponíveis no Portal de Periódicos da CAPES nos últimos cinco anos, na área da educação, descrevem predominante pesquisas realizadas nas e/ou sobre Casas da 
Universidades do Rio Grande do Sul. Os outros dois trabalhos fizeram uma discussão política e social, no campo das ações afirmativas, trazendo importantes contribuições para refletir sobre a assistência e a moradia estudantil, da forma como a mesma vem se constituindo no Brasil, a partir de alguns marcos legais, como o REUNI e o PNAES.

\section{Referências}

BARRETO, Dalton. Moradias estudantis das universidades federais do sul do Brasil: reflexões sobre as políticas de gestão universitária. Dissertação (mestrado) - Universidade Federal de Santa Catarina, Centro Sócio-Econômico. Programa de Pós-Graduação - Mestrado Profissional em Administração Universitária. Florianópolis, SC, 2014. 167 p.

BIEMBENGUT, M. S. Mapeamento na pesquisa educacional. Rio de Janeiro: Ciência Moderna, 2008.

BRASIL. Constituição (1946). Constituição dos Estados Unidos do Brasil: promulgada em 18 de setembro de 1946. Organização do texto: Fernando de Mello Vianna. Disponível em: http://www2.camara.leg.br/legin/fed/consti/1940-1949/constituicao-1946-18-julho-1946365199-publicacaooriginal-1-pl.html Acesso em: 02 set 2018.

Lei $n^{\circ}$ 4.024, de 20 de dezembro de 1961. Fixa as Diretrizes e Bases da Educação Nacional. Diário Oficial [da] República Federativa do Brasil, Brasília, DF, 20 dez. 1961. Disponível em: http://www2.camara.leg.br/legin/fed/lei/1960-1969/lei-4024-20-dezembro1961-353722-publicacaooriginal-1-pl.html. Acesso em: 02 set. 2018.

Constituição (1988). Constituição da República Federativa do Brasil. Coleção de leis da República Federativa do Brasil, Brasília, DF, 1988. Disponível em http://www.planalto.gov.br/ccivil_03/Constituicao/Constituicao.htm. Acesso em: 20 set 2018.

Lei de Diretrizes e Bases da Educação Nacional. Lei número 9394, 20 de dezembro de 1996.

Decreto $n^{\circ} 7.234$ de 19 de julho de 2010: dispõe sobre o Programa Nacional de Assistência Estudantil - PNAES. Diário Oficial [da] União, Brasília, DF, n. 5, p. 261.794, 1 jul. 2010. Seção 1.

CABRAL JUNIOR, Luis Roberto Gulart; GONÇALVES, Jean Carlo Flores; COSTA, José Ricardo Caetano. Moradia e Educação: análise empírica e crítica da política assistencial oferecida aos/às moradores/as das casas de estudantes da universidade federal do Rio Grande - FURG. In.: Brazilian Journal Of Empirical Legal Studies, 01 November 2017, v.4(3).

GOMES, J. B. B. Ações afirmativas: aspectos jurídicos. In: Vários Autores, Racismo no Brasil. São Paulo, Petrópolis/ABONG, 2002.

HERMANN, Gustavo da; COSTA, Benhur Pinós. Geografia e estudo do lugar: a casa do Estudante Universitário II - UFSM/Santa Maria/RS. In: Boletim Geográfico Do Rio Grande Do Sul, 01 April 2017, Issue 29, pp.76-93. 
HINTERHOLZ, Marcos Luiz. tácitas e marginais: memórias das casas de estudante autônomas de porto alegre e as possibilidades para a história da educação, In: História da Educação, 2017, v.21(51), pp.435-448.

, Marcos Luiz. Casa do Estudante Universitário Aparício Cora de Almeida

(1963-1981). In: Espacio, Tiempo Y Educación, 2018, v.5(1), pp.139-157.

JESUS, Luciano Nascimento de; MAYER, Andre Luiz Monteiro; DE CAMARGO, Pedro Luiz Teixeira. Programa Nacional de assistência estudantil: do protagonismo da une aos avanços da luta por direitos, promovidos pelo FONAPRACE (PNAES: da UNE a FONAPRACE). In: Acta Scientiarum. Education (UEM), 2016, V.38(3), pp.247(11).

MAURELL, Joice Rejane Pardo; MACHADO, Celiane Costa. Concepções de ingressantes da moradia estudantil sobre as disciplinas Cálculo. In: Revista Latino Americana de Estudos em Cultura e Sociedade, 01 February 2018, v.4.

SILVA, Guilherme da; POWEL, Arthur. Microagressões no ensino superior nas vias da Educação Matemática. In: Revista Latinoamericana de Etnomatemática, Oct 2016-Jan 2017, v.9(3), pp.44-76.

http://sencebrasil.blogspot.com/p/sobre-sence.html, acessado em 11 de jan de 2019, as $22 \mathrm{~h} 30 \mathrm{~min}$.

http://portal.mec.gov.br/reuni-sp-9331884, acessado em 11 de jan de 2019, as 22h45min. 